\title{
Nanoscale Zr-containing precipitates; a solution for significant improvement of high-temperature strength in Al-Si-Cu-Mg alloys
}

Mehdi Rahimian ${ }^{\text {a }}$, Sajjad Amirkhanlou ${ }^{\text {a }}$, Paul Blake ${ }^{\text {b }}$, Shouxun Ji ${ }^{\text {a,* }}$

a Brunel Centre for Advanced Solidification Technology (BCAST), Brunel University London, Uxbridge, Middlesex UB8 3PH, UK

${ }^{\mathrm{b}}$ Engineering Centre, Jaguar Land Rover, Abbey Road, Coventry, CV34 4LF, UK

* Corresponding author: Tel.: +44 1895 266663, Fax: +44 1895 269758, Email:

Shouxun.Ji@brunel.ac.uk

\section{Abstract:}

This work aims to reveal the valuable role of $\mathrm{Zr}$ in cast $\mathrm{Al}-\mathrm{Si}-\mathrm{Cu}-\mathrm{Mg}$ alloys utilised at elevated temperatures. The Al7Si2Cu0.2Zr alloy, subjected to well-tuned heat treatment process, was benchmarked against the conventional Al7Si0.5Cu alloy. Microstructural investigation showed that the main strengthening phases in the Al7Si2Cu0.2Zr alloy are $\theta^{\prime}$, Q', Al-Si-Cu-Zr and Al-Si-Zr precipitates. Two Zr-containing precipitates (Al-Si-Cu-Zr and $\mathrm{Al}-\mathrm{Si}-\mathrm{Zr}$ ) with the size of $80-200 \mathrm{~nm}$ are formed during solutionising at530 ${ }^{\circ} \mathrm{C}$, which can be considered as the first ageing step. Other two Cu-containing precipitates ( $\theta^{\prime}$ and $\left.\mathrm{Q}^{\prime}\right)$ at the size of $20 \mathrm{~nm}$ are formed during ageing $\left(170{ }^{\circ} \mathrm{C}\right)$. Nano-sized Zr-containing precipitates are mostly exhibited elliptical morphology with coherent/semi-coherent interfaces with the $\alpha$-Al matrix, making them more stable at elevated temperatures. As a result, the yield strength is improved at room temperature from 261 to $291 \mathrm{MPa}$, and the ultimate tensile strength (UTS) is improved from 282 to $335 \mathrm{MPa}$ for the Al7Si2Cu0.2Zr alloy, compared with the Al7Si0.5Cu alloy. Moreover, the mechanical properties are significantly improved at elevated temperatures. The yield strength and UTS at $200{ }^{\circ} \mathrm{C}$ are 177 and $186 \mathrm{MPa}$, respectively, for the Al7Si0.5Cu alloy. But these are224 and $246 \mathrm{MPa}$, respectively, for the Al7Si2Cu0.2Zr 
alloy. The improvement of mechanical properties at elevated temperatures is mainly attributed to the refined microstructure and the precipitation of strengthening phases containing slow-diffused $\mathrm{Zr}$ element to retard the precipitation coarsening. Furthermore, the addition of $\mathrm{Cu}$ changes the precipitates from $\theta^{\prime}$ and $\beta^{\prime \prime}$ in the Al7Si0.5Cu alloy to $\theta^{\prime}$ and $\mathrm{Q}^{\prime}$ in the Al7Si2Cu0.2Zr alloy which, in turn, induce a complementary effect on the improvement of mechanical properties.

Keywords: Aluminium alloys, Microstructure, Mechanical properties, Heat treatment, Phase transition, Precipitation strengthening

\section{Introduction}

The reduction of fuel consumption and concomitant decrease of $\mathrm{CO}_{2}$ emission are taken into account as remarkable necessities for the advanced automotive industries to keep their users at highly competitive market. Diesel and direct fuel injection gasoline engines’ performance can be promoted by increasing the combustion pressure and temperature in engines [1]. Among aluminium alloys, Al-Si-Cu-Mg are the most versatile alloys, comprising $85 \%$ to $90 \%$ of the total aluminium cast parts produced for automotive industry [1,2]. However, since most of the hypoeutectic Al-Si-Cu-Mg alloys used for the production of engine blocks and cylinder head suffer from the significant drop in their performance at temperatures higher than $150{ }^{\circ} \mathrm{C}$, a wide range of investigations have been derived on the increase of engine performance at temperatures over $150{ }^{\circ} \mathrm{C}$. At high temperatures, the alloy's precipitates such as $\beta^{\prime \prime}$ and $\theta^{\prime}$ which maintain the alloy strength at room temperature are usually coarsened or dissolved. As a result, the lack of strengthening phases leads to the considerable decline of alloy performance that limits their practical applications in engine blocks, cylinder heads, or heat shields [3-7]. Although higher $\mathrm{Cu}$ content improves the mechanical properties via forming a higher fraction of $\mathrm{Al}_{2} \mathrm{Cu}$ phase, the concentrations of $\mathrm{Si}$ and $\mathrm{Cu}$ in the industrial 
$\mathrm{Al}-\mathrm{Si}$ based alloys have reached their limits because the addition of $\mathrm{Cu}$ increases corrosively and shrinkage porosities [8].

Cast aluminium alloys can be strengthened through various mechanisms including solidsolution hardening, grain refinement and precipitate hardening, among which precipitation hardening is used to fortify castings for high temperature applications. Historically, most efforts to develop high-strength, thermally-stable $\mathrm{Al}$ alloys have sought alloying elements that exhibit both limited solid-solubility at ageing temperature and low diffusivity in Al. This approach was originally promoted by Adam [9] who argued, based on diffusion-controlled coarsening theory, that dispersed phases formed from such alloying additions would be resistant to Ostwald ripening $[8,10]$. Borne out of these ideas are the rapidly-solidified alloys based on the eutectic Al-Fe system. These include the well-known Al-Fe-V-Si alloys developed by Skinner et al. [11,12], as well as more complex Al-Fe based systems with ternary and often quaternary additions such as Ce, Ni, Co, Zr, Mo, V [9,13]. These alloys, however, derive their high-temperature strength from a large volume fraction of stable precipitates that are formed directly from the melt during rapid solidification [5].

In order to improve high temperature mechanical properties of cast Al-Si-Cu-Mg alloys manufactured by commercial casting processes, such as gravity die casting, efforts have been made to modify the existing alloys with new alloying elements $[14,15]$, which generally have limited solid-solubility at ageing temperatures for enhancing the precipitates strengthening and lowering the diffusivity in aluminium for retarding the Ostwald ripening $[8,16]$. Several studies have been carried out to evaluate the effect of different alloying elements such as $\mathrm{Ni}$, Fe, Cr, Ti, V, Sc and Zr on high temperature mechanical properties of cast Al-Si alloys [1731]. Those phases consisting of fine Fe and homogeneously dispersed Fe phases can 
potentially improve mechanical properties [32]. However, presence of Fe in the Al-Si-Cu-Mg alloy led to the formation of the needle-shaped $\beta$-Al ${ }_{5} \mathrm{FeSi}$ phase, which is responsible for the reduction of alloy ductility [22,33,34]. Addition of $\mathrm{Ni}$ in the Al-Si-Cu-Mg alloy causes a reduction in alloy strength at room temperature mainly due to a decrease in the available $\mathrm{Cu}$ for precipitation strengthening through forming $\mathrm{Al}_{3} \mathrm{CuNi}$. An increase in content of the $\mathrm{Al}_{3} \mathrm{CuNi}$ and $\mathrm{Al}_{9} \mathrm{NiFe}$ phases is also responsible for some reduction in ductility [4]. It is found that the increase of $\mathrm{Cr}$ content exhibits a detrimental effect on the elevated temperature tensile strength of eutectic Al-Si-Cu-Mg alloys [35]. Although Ti has a small diffusivity in $\mathrm{Al}$, only a small concentration of $\mathrm{Ti}$ is incorporated in the precipitates [36]. However, $\mathrm{Ti}$ is not as effective as $\mathrm{Zr}$ at reducing precipitate coarsening and hardening $\mathrm{Al}$ alloys. The disparity of solid and liquid solubility of $\mathrm{Ti}$ in $\mathrm{Al}$ is much greater than that of $\mathrm{Zr}$ in $\mathrm{Al}$. Thus, relatively small liquid solubility of $\mathrm{Ti}$ in $\mathrm{Al}$ limits the amount of solute retained in $\mathrm{Al}$ solid solution during solidification [37]. Although $\mathrm{V}$ and $\mathrm{Hf}$ exhibit low diffusion rate in $\alpha$-Al, solubility of V and Hf in liquid state is lower than that in the solid state. Hence, few V and Hf precipitates are normally formed after solidification at room temperature [37]. Sc was found to form a shallow solvus curve allowing for precipitation strengthening, and form thermodynamically stable $\mathrm{Al}_{3} \mathrm{Sc}$ phase [37], but this element is not affordable to be used in automotive industries due to its high cost. However, as an relatively cost effective element, $\mathrm{Zr}$ has the smallest diffusion rates and lattice parameter mismatch with $\mathrm{Al}$ matrix $[37,38]$. The Zr-containing intermetallics in pure $\mathrm{Al}$ and $\mathrm{Al}-\mathrm{Si}$ alloy have been found thermodynamically stable at elevated temperatures. Therefore, the addition of $\mathrm{Zr}$ can prevent dislocation climbing and reduce the precipitate coarsening at elevated temperatures [39-41].

The effect of $\mathrm{Zr}$ addition on the pure aluminium is discussed in previous studies [36,37]. However, commercially used $\mathrm{Al}$ alloys contain high level of alloying elements making more 
difficult to study Zr-containing phases due to the presence of high amount of solute alloying elements in the $\mathrm{Al}$ matrix and also their interaction with Zr. Although recent studies demonstrated the constructive effect of $\mathrm{Zr}$ on the mechanical properties of cast $\mathrm{Al}-\mathrm{Si}-\mathrm{Cu}-\mathrm{Mg}$ alloys, [18,22,33], it is still unclear how Zr contributes in strengthening of Al-Si-Cu-Mg cast alloys having high amount of $\mathrm{Si}$ and $\mathrm{Cu}$ and low solidification rate. Furthermore, previous studies focused more on the effect of $\mathrm{Zr}$ on the mechanical properties rather than figuring out the microstructural transition occurs due to the addition of $\mathrm{Zr}$ and makes the alloy stronger at elevated temperatures. In previous studies the formation of large intermetallics during solidification was correlated to the mechanical properties improvement in Al-Si-Cu-Mg alloys, while this study reveals the formation of nano-sized $\mathrm{Zr}$-containing phases whose size and chemical composition differs from Zr-containing phases forming in binary Al-Zr system.

Therefore, the present study aims to understand the interaction of $\mathrm{Si}, \mathrm{Cu}$ and $\mathrm{Zr}$ in the cast Al-Si-Cu-Mg alloys produced by gravity casting. The comparison study was carried out for the industrially popular Al7Si0.5Cu alloy and the Al7Si2Cu0.2Zr alloy having modified amount of $\mathrm{Cu}$ and $\mathrm{Zr}$. The tensile strength at ambient temperature and at $200{ }^{\circ} \mathrm{C}$ were studied and compared for these two alloys. The microstructures under as-cast and T6 conditions were thoroughly studied by SEM and TEM to reveal the mechanism of property improvement. The discussions are focused on the contribution of $\mathrm{Zr}$ on the formation of various phases in $\mathrm{Al}-\mathrm{Si}$ $\mathrm{Cu}-\mathrm{Mg}$ alloys. Moreover, the role of $\mathrm{Cu}$ and $\mathrm{Zr}$ for the improvement of elevated temperature mechanical properties of gravity cast $\mathrm{Al}-\mathrm{Si}-\mathrm{Cu}-\mathrm{Mg}$ alloys is disclosed.

\section{Experimental procedure}

The commercially available EN-AC-42000 (Al7Si0.5Cu) alloy was used as baseline material in the present study. For making castings from Al7Si0.5Cu alloy, the EN-AC-42000 alloy 
was melted at $740{ }^{\circ} \mathrm{C}$. For making the Al7Si2Cu0.2Zr alloy, the master alloys of Al-50 wt.\% $\mathrm{Si}, \mathrm{Al}-10 \mathrm{wt} . \% \mathrm{Ti}$, pure $\mathrm{Al}$ and pure $\mathrm{Mg}$ ingots were weighted in a required ratio and melted at $740{ }^{\circ} \mathrm{C}$ together with $\mathrm{Al}-10$ wt.\% Zr master alloy and pure $\mathrm{Cu}$ ingots. The alloys were melted in the electrical resistance furnace (Carbolite) at $740{ }^{\circ} \mathrm{C}$. When the melt was fully homogenised, the melt was subjected to degassing, during which argon was blown into the melt by a commercial rotatory degasser at $400 \mathrm{rpm}$ for $3 \mathrm{~min}$. Thereafter, the melt was poured into the boron nitride painted steel mould, designed based on ASTM B108 standard [42], to produce dog-bone shape tensile specimens. Chemical composition analysis was carried out using a Perkin-Elmer Optima 5300 dual view ICP-AES. The results are shown in the Table 1. The specimens were subjected to the T6 heat treatment consisting of solutionising at $530{ }^{\circ} \mathrm{C}$ for $6 \mathrm{~h}$ followed by artificial ageing at $160{ }^{\circ} \mathrm{C}$ for $24 \mathrm{~h}$ in air-circulating furnace (Carbolite).

Specimens for microstructural characterization were prepared using standard metallographic technique with a final polish to the mirror-like surface using colloidal alumina. The grain structure was revealed via electro-etching method in which specimens were etched under voltage of $5 \mathrm{VDC}$ in the Baker's etchant solution containing $200 \mathrm{ml} \mathrm{H}_{2} \mathrm{O}$ and $10 \mathrm{ml}$ Fluoroboric acid (35\%). The microstructure of as-cast and heat-treated specimens were investigated by several tools. Grain structure characterisation was performed using Zeiss Scope A1 optical microscope in polarised mode. Quantitative analysis of the microstructure was performed using AxioVision Rel. 4.8 software. Microstructural evaluation was also carried out by JEOL 2100F (JEOL Ltd.) high resolution transmission electron microscopy (HRTEM) and SUPRA 35VP (Carl-Zeiss Company) field emission scanning electron microscopy (FE-SEM), both of which were equipped by an energy dispersive X-ray spectroscopy (EDS). The operating voltages of TEM and FE-SEM were adjusted on 200 and $20 \mathrm{kV}$, respectively. The TEM samples were cut from the aged Al7Si0.5Cu and 
Al7Si2Cu0.2Zr specimens and were grinded to less than $100 \mu \mathrm{m}$ thicknesses. $3 \mathrm{~mm}$ diameter samples were punched, and the further reduction of thickness was obtained by Gatan precision ion polishing system (PIPS) adjusted at $5.0 \mathrm{kV}$ and at an incident angle of $4^{\circ}$.

The room and high temperature tensile tests were performed by Instron 5500 Universal Electromechanical Testing Systems equipped with Bluehill software and a $50 \mathrm{kN}$ load cell. Room temperature tensile test was carried out according to ASTM E8/E8M [43], while high temperature tensile test was conducted according to the ASTM E21 [44] in which specimens were exposed to the $200{ }^{\circ} \mathrm{C}$ for at least $40 \mathrm{~min}$ in an electrically heated air-circulating chamber before performing the tensile test. Dynamic strain gauge extensometer was utilized for strain measurement. The tensile test results, with applied strain rate of $1 \mathrm{~mm} / \mathrm{min}$, were extracted from at least 6 tensile tests for each defined condition.

\section{Results and discussion}

\subsection{Grain refinement}

Fig. 1 shows the variation of grain sizes between two alloys and the effect of heat treatment on the grain size. Clearly, the Al7Si2Cu0.2Zr alloy comprises finer grains in comparison to the Al7Si0.5Cu alloy. The average grain size of the as-cast Al7Si0.5Cu alloy was $402 \mu \mathrm{m}$, while it reduced to $207 \mu \mathrm{m}$ in the as-cast Al7Si2Cu0.2Zr alloy, which is almost $50 \%$ reduction. According to the theory of heterogeneous nucleation [45], the grain size is controlled by two factors: undercooling of melt and nucleation sites. The addition of $\mathrm{Zr}$ results in the formation of $\mathrm{Zr}$-containing intermetallics which are stable at temperatures over $650{ }^{\circ} \mathrm{C}$ and can act as nucleation sites [46]. The effect of $\mathrm{Zr}$ on the grain refinement of $\mathrm{Al}$ alloys was comprehensively discussed by Wang et al. [47] and also seen in other studies [48]. It is observed that the addition of 0.1 wt. \% Zr does not induce a tangible effect on grain size, 
while further addition of $\mathrm{Zr}$ at a level over its maximum solubility ( $\sim 0.11 \% \mathrm{Zr}$ ) can decrease the grain size considerably. A sharp reduction of grain size was seen at $0.2 \mathrm{wt}$ \% $\mathrm{Zr}$ content, but grain refinement decelerates at $\mathrm{Zr}$ percentages over $0.2 \mathrm{wt} . \%$. In order to verify the nucleation potency of $\mathrm{Al}_{3} \mathrm{Zr}$ particles, particularly those located at the grain centre, the crystallographic relationship between $\mathrm{Al}$ and $\mathrm{Al}_{3} \mathrm{Zr}$ was studied by E2EM model, EBSD and TEM observations [48]. The results showed that there is a good match between some directions and planes of $\mathrm{Al}$ and $\mathrm{Al}_{3} \mathrm{Zr}$ particles. For instance, (114) plain in $\mathrm{Al}_{3} \mathrm{Zr}$ are nearly

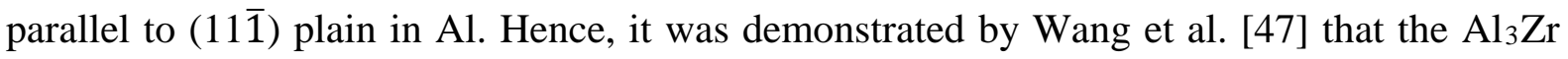
particles act as potent nucleants for Al. It was also shown that smaller misfit and mismatch values between grain refiner and matrix induces higher grain refinement efficiency [49] because of lower interfacial energy between the grain refiners and the solid formed on the grain refiners. Therefore, small mismatches values between $\mathrm{Al}_{3} \mathrm{Zr}$ and $\mathrm{Al}$ indicates the high grain refining efficiency of $\mathrm{Al}_{3} \mathrm{Zr}$ for $\mathrm{Al}$ [47]. Moreover, broader particle sizes were observed for $\mathrm{Al}_{3} \mathrm{Zr}$ particles $(0-115 \mu \mathrm{m})$ as compared with $\mathrm{TiB}_{2}$ particles $(0-6 \mu \mathrm{m})$. Very slow cooling rate $\left(1 \mathrm{~K} \mathrm{~s}^{-1}\right)$ and higher $\mathrm{Zr}$ content also result in the formation of larger $\mathrm{Al}_{3} \mathrm{Zr}$ particles. According to the free growth theory, grains initially nucleate on the biggest nucleating particles since smaller undercooling is required, then with increasing the undercooling smaller particles act as nucleation sites $[47,50]$. It is also seen that grain size was basically not affected by heat treatment, indicating that no considerable grain growth occurred during heat treatment (Figs. 1b and d). The grain sizes after heat treatment were $397 \mu \mathrm{m}$ and $201 \mu \mathrm{m}$ in the Al7Si0.5Cu and Al7Si2Cu0.2Zr alloys, respectively.

\subsection{Phase analysis}

Figs. 2-4 show the SEM micrographs of as-cast and heat-treated specimens for the Al7Si0.5Cu and Al7Si2Cu0.2Zr alloys. The Fe-rich intermetallics in Fig. 2a have needle 
shape morphology. The same type of Fe-rich intermetallics was also identified after heat treatment (Fig. 2b), confirming that the Fe-rich intermetallics were not dissolved during heat treatment. According to the Figs. 2a and 3a, Si phases were connected in both alloys under as-cast condition. These were obviously refined and showed the round shapes after heat treatment (Figs. 2b and 4a). In other words, Si phases were modified by heat treatment. The morphological modification of the Si phases can be attributed to the addition of the Sr and heat treatment. The recent investigation via atom probe tomography and HRTEM [51] has confirmed that Si morphology corresponds to the competing growth of $\mathrm{Al}$ and $\mathrm{Si}$ phases in Al-Si alloys. The flaky eutectic structure of Si forms when the Si structures grow in advance with respect to the $\mathrm{Al}$ phase. Therefore, the morphological transition of Si eutectic from flaky to round-shape occurs when both $\mathrm{Al}$ and Si phases grow simultaneously at a common growth front. The mechanical obstruction and absorption of Sr modifier into the Si crystal reduces Si growth rate. Since the amount of Al trapped during solidification is higher than its solubility limit in Si, Al diffuses and forms defects. High defect density of Al-Sr segregations was identified in the modified Si structure. As the trapped Al in the Si phases in the Sr modified alloy is four times higher than that in the unmodified alloy which, in turn, exhibits the incorporation of the large fractions of $\mathrm{Al}$ and $\mathrm{Sr}$ into the Si phase [51].

The phase analysis of as-cast Al7Si2Cu0.2Zr alloy, using EDS, is displayed in Figs. 3b-e. Fig. 3a shows that the diversity of the phases in the as-cast Al7Si2Cu0.2Zr alloys is higher than that in as-cast Al7Si0.5Cu alloy shown in Fig. 2a. Although these two alloys contained the Fe-containing phases with the same format of $\mathrm{Al}_{15}(\mathrm{Fe}, \mathrm{Mn})_{3} \mathrm{Si}_{2}$, the as-cast Al7Si2Cu0.2Zr alloy comprised other intermetallic phases including Al-Si-Zr-Ti phase, $\mathrm{Al}_{2} \mathrm{Cu}(\theta)$ and $\mathrm{Al}_{5} \mathrm{Mg}_{8} \mathrm{Si}_{6} \mathrm{Cu}_{2}(\mathrm{Q})$ phases. Figs. 4a and b show the SEM micrographs of the heat-treated Al7Si2Cu0.2Zr alloy. The fine and round shape phases in Fig. 4a were identified 
as $\mathrm{Si}$, Fe-containing phases (Fig. 4c) and Al-Si-Zr-Ti phase (Fig. 4d). These phases were expected to be formed during solidification and not dissolved or partially dissolved during heat treatment because of their stability at elevated temperatures [18,52]. The sub-micron AlSi-Zr and Al-Si-Cu-Zr phases were also observed Figs. 4f and g.

\subsection{Nanoscale Zr-containing precipitates}

The bright field TEM (BF-TEM) micrographs of Al7Si0.5Cu alloy taken along the [001] $\mathrm{Al}$ axis is shown in Fig. 5a, which exhibits the presence of nano-sized $\theta^{\prime}$ and $\beta^{\prime \prime}$ precipitates in the alloy after T6 heat treatment. Both $\theta^{\prime}$ and $\beta^{\prime \prime}$ were needle-shaped. However, a white shadow was often observed at the vicinity of black needle-shape part in the $\beta^{\prime \prime}$ due to the strain induced by the formation of $\beta^{\prime \prime}$. As shown in Fig. 5b, the selected area diffraction pattern (SADP) of the Al7Si0.5Cu alloy revealed the diffraction patterns of both $\theta^{\prime}$ and $\beta^{\prime \prime}$ precipitates. The diffraction of $\alpha-\mathrm{Al}$ matrix appeared as strong bright points, while the diffraction pattern of $\theta^{\prime}$ and $\beta^{\prime \prime}$ precipitates were those diffraction streaks passing among the Al diffraction pattern. Based on the diffraction pattern of the $\theta^{\prime}$ and $\beta^{\prime \prime}$ precipitates, both phases were in the metastable condition, indicating peak strength state for the heat-treated Al7Si0.5Cu alloy. Fig. 5c shows the high resolution TEM micrograph of the embedded $\beta^{\prime \prime}$ phases aligned to the [100] direction. Fig. 5d exhibits the fast Fourier transmission (FFT) micrograph of $\beta^{\prime \prime}$ precipitate, marked by rectangular in Fig. 5c, which confirmed the presence of $\beta$ " phase in the microstructure.

Figs. 6 and 7 show the precipitates in the Al7Si2Cu0.2Zr alloy. Basically, four types of precipitates were found in the $\alpha$-Al matrix of Al7Si2Cu0.2Zr alloy. These precipitates included two Zr-containing precipitates (Al-Si-Cu-Zr and Al-Si-Zr) with the size of 80-200 
nm (Fig. 6) and two Cu-containing precipitates ( $\theta^{\prime}$ and $\left.Q^{\prime}\right)$ which were around 20-30 nm (Fig. 7).

Fig. 6a shows two types of Zr-containing phases, which were identified as Al-Si-Zr-Cu and Al-Si-Zr phases. The corresponding SADP in Fig. $6 \mathrm{~b}$ confirmed the presence of those phases. The size of oval-shaped Al-Si-Zr precipitates were $80-200 \mathrm{~nm}$. In order to determine the formation stage of $\mathrm{Zr}$-containing precipitates, the microstructure of the specimens under ascast and solutionising condition were examined. Figs. 8a and b show the high-resolution SEM micrographs of the Al7Si2Cu0.2Zr alloy under as-cast and solutionising conditions, respectively. The as-cast microstructure Fig. 8a exhibits a microstructure without any nanoscale Zr precipitates, while the Zr-containing precipitates formed during the solutionising treatment $\left(530{ }^{\circ} \mathrm{C}, 6 \mathrm{~h}\right)$ are obvious in Fig. 8b. In fact, the solutionising heat treatment acted as an ageing treatment for formation of $\mathrm{Zr}$-containing precipitates. Since $\mathrm{Zr}$ is a slow diffusion element, Zr-containing phases form normally at temperatures higher than $400{ }^{\circ} \mathrm{C}$ [53]. The formation of $\mathrm{Al}_{3} \mathrm{Zr}$ precipitates in binary $\mathrm{Al}-\mathrm{Zr}$ system at temperatures above 400 ${ }^{\circ} \mathrm{C}$ was already reported in previous studies [54].

Figs. $6 \mathrm{~d}$ and $\mathrm{f}$ show the EDS-TEM of the Al7Si2Cu0.2Zr alloy which exhibits the presence of the $\mathrm{Al}-\mathrm{Si}-\mathrm{Cu}-\mathrm{Zr}$ and $\mathrm{Al}-\mathrm{Si}-\mathrm{Zr}$ precipitates. It is reported that $\mathrm{Zr}$ forms $\mathrm{Al}_{3} \mathrm{Zr}$ precipitates in binary Al-Zr system [54], however, addition of high amount of Si results in formation of (Al,Si)3Zr phase [26,53]. AlsZr have spherical shape and their size normally is round $20 \mathrm{~nm}$ [53], while the addition of high amount of Si results in changing of the size and shape of Zrcontaining phase, which is demonstrated by as Gao et al. [53] for Al-3Si-0.5Zr system. They observed that Zr-containing phases in Al-3Si-0.5Zr system has coarse elliptical shaped morphology with the average size of $100 \mathrm{~nm}$ [53], which is in agreement with the results of 
present investigation. Based on the Fig. 6d, it seems that in Al7Si2Cu0.2Zr alloy, due to the high amount of $\mathrm{Cu}$, in some cases $\mathrm{Cu}$ is also partitioned into the $\mathrm{Al}-\mathrm{Si}$-Zr phases resulting in the formation of the $\mathrm{Al}-\mathrm{Si}-\mathrm{Zr}-\mathrm{Cu}$ phases. In $\mathrm{Al}-\mathrm{Si}-\mathrm{Zr}-\mathrm{Cu}$ phase, $\mathrm{Cu}$ substituted $\mathrm{Al}$ as a result of which $\left(\mathrm{Al}_{1-\mathrm{x}-\mathrm{y}}, \mathrm{Si}_{\mathrm{x}}, \mathrm{Cu}_{\mathrm{y}}\right)_{3} \mathrm{Zr}$ can be proposed for this phase [55].

Unlike the $\mathrm{Al}-\mathrm{Si}-\mathrm{Cu}-\mathrm{Zr}$ and $\mathrm{Al}-\mathrm{Si}-\mathrm{Zr}$ precipitates formed after solutionising treatment, $\theta^{\prime}$ and Q' phases formed after ageing treatment. Higher magnification TEM micrograph of the Al7Si2Cu0.2Zr alloy after ageing taken along the [100] Al axis, Fig. 7a, reveals uniform distribution of the $\theta^{\prime}$ and $\mathrm{Q}^{\prime}$ phases whose size were between 20 and $30 \mathrm{~nm}$, respectively. $\theta^{\prime}$ phases exhibited needle-like morphology with the long axis parallel to $\{100\} \alpha-\mathrm{Al}$ and $\mathrm{Q}^{\prime}$ phases had the rod-shaped morphology laying on the $\{100\} \alpha$-Al. The insert in Fig. 7a is the corresponding SADP of $\theta^{\prime}$ and $\mathrm{Q}^{\prime}$ phases. According to the SADP, Fig. 7a, both $\theta^{\prime}$ and $\mathrm{Q}^{\prime}$ phases were in the metastable condition as they were seen as streaks passing among the $\mathrm{Al}$ diffraction pattern. Fig. 7b shows the HRTEM micrograph of the $\theta^{\prime}$ phase forming a coherent interface with $\alpha-\mathrm{Al}$ and the insert displays the FFT of $\theta^{\prime}$ phase. Fig. 7c displays the HRTEM micrograph of the $\mathrm{Q}^{\prime}$ phase taken along the (100) $\alpha-\mathrm{Al}$ zone axis together with the insert which exhibits the FFT of the Q' phase. Hence, it is concluded that higher Cu level led to the formation of $\theta^{\prime}$ and $\mathrm{Q}^{\prime}$ phase in the Al7Si2Cu0.2Zr alloy, instead of the formation of $\beta^{\prime \prime}$ and $\theta^{\prime}$ which were identified in the Al7Si0.5Cu alloy.

Fig. 9 shows the morphology of Al-Si-Zr phases in Al7Si2Cu0.2Zr alloy. Smaller edge in the Al-Si-Zr precipitate showed incoherent interface in Fig. 9a, while the coherent interface was observed at the larger interfaces with Al the matrix Fig. 9b. Coherent interface could maximize the strengthening effect of the dispersed precipitates. Furthermore, the coherency could minimize the surface energy per unit area of the interface, resulting in stability at 
elevated temperatures by reducing the driving force for precipitate coarsening [16]. Therefore, the formation of semi-coherent precipice was an important factor, which can potentially improve the mechanical properties at elevated temperatures.

\subsection{Mechanical properties}

According to the Figs. 10 and 11, the Al7Si2Cu0.2Zr alloy provided much improved yield strength and UTS in comparison with the Al7Si0.5Cu alloy. At ambient temperature, the Al7Si2Cu0.2Zr alloy had a yield strength of 291MPa and UTS of 335MPa, but the Al7Si0.5Cu alloy had a yield strength of $261 \mathrm{MPa}$ and UTS of $282 \mathrm{MPa}$. The mechanical property enhancement is due to the grain refinement and precipitate formation. While the four different kinds of nano-sized strengthening phases were formed and dispersed homogeneously in the matrix of the Al7Si2Cu0.2Zr alloy, two kinds of strengthening precipitates were found in the $\mathrm{Al} \mathrm{Si} 0.5 \mathrm{Cu}$ alloy. The increment of precipitates volume fraction due to the formation of new precipitates leads to the reduction of distance between precipitates [56]. The formation of $\mathrm{Cu}$ and $\mathrm{Zr}$-containing phases can be interpreted by Orowan and Hall-Petch theories [34]. According to the Orowan mechanism, expressed by Eq. 1 , lower amount of $\lambda$ leads to shorter dislocation movement and the higher improvement of yield strength.

$\Delta \sigma_{\text {orowan }}=\frac{G b}{\lambda}$

In Eq. $1, G$ and $b$ are shear modulus and Burger's vector, respectively [56-58]. The precipitates hinder dislocations gliding to increase the resistance against further deformation under loading. Apart from the precipitate strengthening, grain boundary influences substantially on the yield strength. As shown in Fig. 1, the Al7Si2Cu0.2Zr alloy consists of finer grains than the Al7Si0.5Cu alloy. The enhancement of yield strength through grain refinement has been well documented through Hall-Petch relation [56][56,57]. 
When the testing temperature was increased from ambient temperature to $200^{\circ} \mathrm{C}$, the yield strength was decreased from 291 to $224 \mathrm{MPa}$ and the UTS was declined from 335 to 246 MPa for the heat-treated Al7Si2Cu0.2Zr alloy. Similar trend could be found in the Al7Si0.5Cu alloy. The yield strength was dropped from 261 to $177 \mathrm{MPa}$ and the UTS was decreased from 282 to $186 \mathrm{MPa}$, which was 34 and $37 \%$ of the increment. The significant reduction of yield strength and UTS at $200{ }^{\circ} \mathrm{C}$ corresponds to the softening of alloy on the account of dissolution and coarsening of strengthening phases. At elevated temperatures, dislocations can bypass the obstacles by climbing, which facilitate and accelerate dislocation gliding and concomitant deformation. Also, higher numbers of slip systems are activated with the increase of temperature.

Coarsening phenomenon is defined by Ostwald ripening theory in which larger precipitates tend to grow at the expense of smaller ones to reduce the surface energy per volume of system. The kinetics is governed by the solubility and diffusivity of the precipitate's elements together with the interfacial energy between the precipitate and matrix (Eq. 2). The coarsening rate is determined by:

$k T=k_{0} \exp \left(\frac{-Q_{k}}{R T}\right)$

where $k$ is coarsening rate and $Q_{k}$ is the activation energy for coarsening which is the sum of the diffusion activation energy and solubility [59]. Hence, the coarsening rate of each precipitate is strongly controlled by the bulk diffusion of its elements in the matrix, as the precipitates containing elements which have sluggish diffusivity in Al matrix, particularly at elevated temperatures, retard the precipitate coarsening and reduce the mechanical strength at elevated temperatures. The diffusivity (D) of $\mathrm{Zr}$ in $\alpha$-Al at elevated temperatures, according to the Table 2, is much less than that of $\mathrm{Cu}$. $\mathrm{Zr}$ has a high diffusion activation energy of 242 
$\mathrm{KJ} / \mathrm{mol}$ and low diffusivity of $1.20 \times 10^{-20} \mathrm{~m}^{2} / \mathrm{s}$ at $400{ }^{\circ} \mathrm{C}$ in $\alpha$-Al [36]. It also should be noted that maximum $\mathrm{Zr}$ and $\mathrm{Ti}$ solid solubility in binary $\mathrm{Al}-\mathrm{M}$ alloys at $400{ }^{\circ} \mathrm{C}$ are 0.083 and 0.79 at.\%, respectively, which is much less than Cu solubility at the same temperature which is around 2 at.\%. Thus, the partitioning of $\mathrm{Zr}$ among the $\mathrm{Al}-\mathrm{Si}-\mathrm{Zr}-\mathrm{Cu}$ and $\mathrm{Al}-\mathrm{Si}-\mathrm{Zr}$ precipitates in the Al7Si2Cu0.2Zr alloy leads to the increase of $Q_{k}$ at elevated temperatures, which is capable of retarding the coarsening of Zr-containing precipitates. In addition to the partitioning of $\mathrm{Zr}$ in the $\mathrm{Al}-\mathrm{Si}-\mathrm{Zr}-\mathrm{Cu}$ precipitate in the Al7Si2Cu0.2Zr alloy, $\mathrm{Zr}$ also forms $\mathrm{Al}-\mathrm{Si}-\mathrm{Zr}$ precipitates that exhibit higher resistance against coarsening at $200{ }^{\circ} \mathrm{C}$ and even higher temperatures as $[26,60]$. Therefore, the improvement of mechanical properties in Al7Si2Cu0.2Zr alloy at elevated temperatures is governed by the formation of precipitates containing $\mathrm{Zr}$ element. Moreover, the formation of $\mathrm{Q}^{\prime}$ phase by tuning the $\mathrm{Cu}$ content can significantly increase the resistance of the alloy at elevated temperatures [61].

The Al7Si2Cu0.2Zr alloy showed an elongation of $1.77 \%$ and the Al7Si0.5Cu alloy had an elongation of $2.74 \%$ at ambient temperature (Fig. 12). The reduction of elongation in the Al7Si2Cu0.2Zr alloy is because the increased $\mathrm{Cu}$ content to introduce higher amount of precipitates as well as the formation of shrinkage porosities in the matrix. The addition of $\mathrm{Cu}$ alters the solidification process and forms micro-porosity in the interdendritic area to lower the elongation[62]. However, the elongation of both alloys is maintained at acceptable level for practical applications.

\section{Conclusions}

1 The grain size is $\sim 200 \mu \mathrm{m}$ in the Al7Si2Cu0.2Zr alloy and $\sim 400 \mu \mathrm{m}$ in the Al7Si0.5Cu alloy, confirming a significant reduction of grain size in the Al7Si2Cu0.2Zr alloy. 
2 The main strengthening phases in the Al7Si2Cu0.2Zr alloy are $\theta^{\prime}, \mathrm{Q}^{\prime}, \mathrm{Al}-\mathrm{Si}-\mathrm{Cu}-\mathrm{Zr}$ and Al-Si-Zr precipitates. Two Zr-containing precipitates (Al-Si-Cu-Zr and Al-Si-Zr) with the sizes around $100-200 \mathrm{~nm}$ are formed during solutionising at $530{ }^{\circ} \mathrm{C}$, which can be considered as the first ageing step, while, other two $\mathrm{Cu}$-containing precipitates $\left(\theta^{\prime}\right.$ and $\left.\mathrm{Q}^{\prime}\right)$ with the sizes around $20 \mathrm{~nm}$ are formed during ageing at $170{ }^{\circ} \mathrm{C}$.

3 The Al7Si2Cu0.2Zr alloy offers improved mechanical properties than the Al7Si0.5Cu alloy at ambient and elevated temperatures. At ambient temperature, the yield strength is 291MPa for the Al7Si2Cu0.2Zr alloy, and $261 \mathrm{MPa}$ for the Al7Si0.5Cu alloy. When the testing temperature is at $200^{\circ} \mathrm{C}$, the yield strength is $224 \mathrm{MPa}$ for the Al7Si2Cu0.2Zr alloy and $177 \mathrm{MPa}$ for the Al7Si0.5Cu alloy.

4 Nano-sized Al-Si-Zr phase is found in the primary $\alpha$-Al phase of the Al7Si2Cu0.2Zr alloy, showing elliptical morphology and coherent/semi-coherent in interfaces with the $\alpha$-Al matrix.

5 The improved mechanical properties of Al7Si2Cu0.2Zr alloy at elevated temperatures are mainly due to the formation of nano-scale $\mathrm{Zr}$-containing precipitates showing small diffusivity in $\mathrm{Al}$ matrix at elevated temperatures.

\section{Acknowledgements}

Financial support from Jaguar Range Rover (JLR) [grant number R33232] is gratefully acknowledged.

\section{References}

[1] J.A. Lee, Cast aluminum alloy for high temperature applications, in: S.K. Das (Ed.), Automot. Alloy. 2003, TMS, San Diego, 2003.

[2] A.J. Shahani, X. Xiao, K. Skinner, M. Peters, P.W. Voorhees, Ostwald ripening of 
faceted Si particles in an Al-Si-Cu melt, Mater. Sci. Eng. A. 673 (2016) 307-320.

[3] G. Sha, H. Möller, W.E. Stumpf, J.H. Xia, G. Govender, S.P. Ringer, Solute nanostructures and their strengthening effects in Al-7Si-0.6Mg alloy F357, Acta Mater. 60 (2012) 692-701.

[4] J. Hernandez-Sandoval, G.H. Garza-Elizondo, A.M. Samuel, S. Valtiierra, F.H. Samuel, The ambient and high temperature deformation behavior of $\mathrm{Al}-\mathrm{Si}-\mathrm{Cu}-\mathrm{Mg}$ alloy with minor Ti, Zr, Ni additions, Mater. Des. 58 (2014) 89-101.

[5] K.E. Knipling, D.C. Dunand, D.N. Seidman, Criteria for developing castable, creepresistant aluminum-based alloys - A review, Zeitschrift Fuer Met. Res. Adv. Tech. 97 (2006) 246-265.

[6] M. Zamani, L. Morini, L. Ceschini, S. Seifeddine, The role of transition metal additions on the ambient and elevated temperature properties of Al-Si alloys, Mater. Sci. Eng. A. 693 (2017) 42-50.

[7] S.W. Choi, H.S. Cho, S. Kumai, Titanium as an intermetallic phase stabilizer and its effect on the mechanical and thermal properties of Al-Si-Mg-Cu-Ti alloy, Mater. Sci. Eng. A. 678 (2016) 267-272.

[8] M. E. Fine, Stability and Coarsening of Dispersoids in Aluminum Alloys, in: Y. W. Kim, W. M. Griffith (Eds.), Dispers. Strengthened Alum. Alloy., TMS, Warrendale, 1988.

[9] C.M. Adam, Structure/Property Relationships and Applications of Rapidly Solidified Aluminum Alloys, MRS Proc. 8 (2011) 411.

[10] M.E. Fine, Precipitation hardening of aluminum alloys, Metall. Trans. A. 6 (1975) 625-630.

[11] D.. Skinner, K. Okazaki, High strength al-Fe-V alloys at elevated temperatures produced by rapid quenching from the melt, Scr. Metall. 18 (1984) 905-909. 
[12] D.J. Skinner, R.L. Bye, D. Raybould, A.M. Brown, Dispersion strengthened Al-Fe-VSi alloys, Scr. Metall. 20 (1986) 867-872.

[13] S.K. Shaha, F. Czerwinski, W. Kasprzak, J. Friedman, D.L. Chen, Ageing characteristics and high-temperature tensile properties of $\mathrm{Al}-\mathrm{Si}-\mathrm{Cu}-\mathrm{Mg}$ alloys with micro-additions of Mo and Mn, Mater. Sci. Eng. A. 684 (2017) 726-736.

[14] J. R. Davis, ed., Aluminium and aluminium alloys, in: ASM International, 1998.

[15] H. Ye, An Overview of the Development of Al-Si-Alloy Based Material for Engine Applications, J. Mater. Eng. Perform. 12 (2003) 288-297.

[16] M.E. Fine, Precipitation hardening of aluminum alloys, Metall. Trans. A. 6 (1975) $625-630$.

[17] J. Hernandez-Sandoval, G.H. Garza-Elizondo, A.M. Samuel, S. Valtiierra, F.H. Samuel, The ambient and high temperature deformation behavior of $\mathrm{Al}-\mathrm{Si}-\mathrm{Cu}-\mathrm{Mg}$ alloy with minor Ti, Zr, Ni additions, Mater. Des. 58 (2014) 89-101.

[18] S.K. Shaha, F. Czerwinski, W. Kasprzak, J. Friedman, D.L. Chen, Improving HighTemperature Tensile and Low-Cycle Fatigue Behavior of Al-Si-Cu-Mg Alloys Through Micro-additions of Ti, V, and Zr, Metall. Mater. Trans. A. 46 (2015) 30633078.

[19] P. Sepehrband, R. Mahmudi, F. Khomamizadeh, Effect of $\mathrm{Zr}$ addition on the aging behavior of A319 aluminum cast alloy, Scr. Mater. 52 (2005) 253-257.

[20] S.K. Chaudhury, V. Warke, S. Shankar, D. Apelian, Localized recrystallization in cast Al-Si-Mg Alloy during solution heat treatment: dilatometric and calorimetric studies, Metall. Mater. Trans. A. 42 (2011) 3160-3169.

[21] R. Mahmudi, P. Sepehrband, H.M. Ghasemi, Improved properties of A319 aluminum casting alloy modified with Zr, Mater. Lett. 60 (2006) 2606-2610.

[22] W. Kasprzak, B.S. Amirkhiz, M. Niewczas, Structure and properties of cast Al-Si 
based alloy with $\mathrm{Zr}-\mathrm{V}-\mathrm{Ti}$ additions and its evaluation of high temperature performance, J. Alloys Compd. 595 (2014) 67-79.

[23] T. Gao, X. Zhu, Q. Sun, X. Liu, Morphological evolution of ZrAlSi phase and its impact on the elevated-temperature properties of Al-Si piston alloy, J. Alloys Compd. 567 (2013) 82-88.

[24] K.L. Sahoo, B.N. Pathak, Solidification behaviour, microstructure and mechanical properties of high Fe-containing Al-Si-V alloys, J. Mater. Process. Technol. 209 (2009) 798-804.

[25] X.-G. Chen, M. Fortier, TiAlSi intermetallic formation and its impact on the casting processing in Al-Si alloys, J. Mater. Process. Technol. 210 (2010) 1780-1786.

[26] C. Booth-Morrison, Z. Mao, M. Diaz, D.C. Dunand, C. Wolverton, D.N. Seidman, Role of silicon in accelerating the nucleation of $\mathrm{Al} 3(\mathrm{Sc}, \mathrm{Zr})$ precipitates in dilute $\mathrm{Al}-$ Sc-Zr alloys, Acta Mater. 60 (2012) 4740-4752.

[27] Y. Li, Y. Yang, Y. Wu, L. Wang, X. Liu, Quantitative comparison of three Nicontaining phases to the elevated-temperature properties of Al-Si piston alloys, Mater. Sci. Eng. A. 527 (2010) 7132-7137.

[28] Y. Li, Y. Yang, Y. Wu, Z. Wei, X. Liu, Supportive strengthening role of Cr-rich phase on Al-Si multicomponent piston alloy at elevated temperature, Mater. Sci. Eng. A. 528 (2011) 4427-4430.

[29] Y. Meng, J. Cui, Z. Zhao, Y. Zuo, Effect of vanadium on the microstructures and mechanical properties of an $\mathrm{Al}-\mathrm{Mg}-\mathrm{Si}-\mathrm{Cu}-\mathrm{Cr}-\mathrm{Ti}$ alloy of 6XXX series, J. Alloys Compd. 573 (2013) 102-111.

[30] T.V. Atamanenko, D.G. Eskin, M. Sluiter, L. Katgerman, On the mechanism of grain refinement in Al-Zr-Ti alloys, J. Alloys Compd. 509 (2011) 57-60.

[31] T. Gao, X. Liu, Replacement with Each Other of Ti and Zr in the Intermetallics of Al- 
(Si-)Ti-Zr Alloys, J. Mater. Sci. Technol. 29 (2013) 291-296.

[32] F. Yan, S. Kumar, B.J. McKay, K.A.Q. O’Reilly, Effect of Mn on Fe containing phase formation in high purity aluminium, Int. J. Cast Met. Res. 27 (2013) 202-206.

[33] H.A. Elhadari, H.A. Patel, D.L. Chen, W. Kasprzak, Tensile and fatigue properties of a cast aluminum alloy with Ti, Zr and V additions, Mater. Sci. Eng. A. 528 (2011) 8128-8138.

[34] S.K. Shaha, F. Czerwinski, W. Kasprzak, J. Friedman, D.L. Chen, Monotonic and cyclic deformation behavior of the Al-Si-Cu-Mg cast alloy with micro-additions of Ti, V and Zr, Int. J. Fatigue. 70 (2015) 383-394.

[35] Y. Yang, S.-Y. Zhong, Z. Chen, M. Wang, N. Ma, H. Wang, Effect of Cr content and heat-treatment on the high temperature strength of eutectic Al-Si alloys, J. Alloys Compd. 647 (2015) 63-69.

[36] Keith Edward Knipling, Development of a nanoscale precipitation-strengthened creepresistant aluminum alloy containing trialuminide precipitates, Northwestern University, 2006.

[37] K.E. Knipling, D.C. Dunand, D.N. Seidman, Criteria for developing castable, creepresistant aluminum-based alloys - A review, Zeitschrift Fuer Met. Res. Adv. Tech. 97 (2006) 246-265.

[38] H. Okamoto, Phase diagrams of dilute binary alloys, ASM International, 2002.

[39] O. Izumi, D. Oelschägel, On the decomposition of a highly supersaturated Al-Zr solid solution, Scr. Metall. 3 (1969) 619-621.

[40] M.S. Zedalis, M.E. Fine, Precipitation and ostwald ripening in dilute Al Base-Zr-V alloys, Metall. Trans. A. 17 (1986) 2187-2198.

[41] S. Srinivasan, P.B. Desch, R.B. Schwarz, Metastable phases in the Al3X (X = Ti, Zr, and Hf) intermetallic system, Scr. Metall. Mater. 25 (1991) 2513-2516. 
[42] astm committee, ASTM Volume 02.02 Aluminum and Magnesium Alloys, 2006.

[43] ASTM committee, Standard Test Methods for Tension Testing of Metallic Materials, 2003.

[44] ASTM committee, Standard Test Methods for Elevated Temperature Tension Tests of Metallic Materials, 2003.

[45] Kurz W, Fisher DJ, Fundamentals of solidification, Fourth rev, Trans Tech Publications, Aedermannsdorf, Switzerland, 1998.

[46] A. Yu, C. Yang, P. He, F. Liu, S. Wang, H. Chen, Effect of La,Zr micro-alloying on the microstructure and mechanical properties of Al-5Mg-0.2Ti alloy, Xiyou Jinshu Cailiao Yu Gongcheng/Rare Met. Mater. Eng. 45 (2016) 760-764.

[47] F. Wang, D. Qiu, Z.L. Liu, J.A. Taylor, M.A. Easton, M.X. Zhang, The grain refinement mechanism of cast aluminium by zirconium, Acta Mater. 61 (2013) 56365645.

[48] W. Liu, W. Xiao, C. Xu, M. Liu, C. Ma, Synergistic effects of Gd and Zr on grain refinement and eutectic Si modification of Al-Si cast alloy, Mater. Sci. Eng. A. 693 (2017) 93-100.

[49] M.X. Zhang, P.M. Kelly, M.A. Easton, J.A. Taylor, Crystallographic study of grain refinement in aluminum alloys using the edge-to-edge matching model, Acta Mater. 53 (2005) 1427-1438.

[50] T.E. Quested, A.L. Greer, Grain refinement of Al alloys: Mechanisms determining ascast grain size in directional solidification, Acta Mater. 53 (2005) 4643-4653.

[51] J. Barrirero, M. Engstler, N. Ghafoor, N. De Jonge, M. Odén, F. Mücklich, Comparison of segregations formed in unmodified and Sr-modified Al-Si alloys studied by atom probe tomography and transmission electron microscopy, J. Alloys Compd. 611 (2014) 410-421. 
[52] D.. Skinner, K. Okazaki, High strength al-Fe-V alloys at elevated temperatures produced by rapid quenching from the melt, Scr. Metall. 18 (1984) 905-909.

[53] T. Gao, A. Ceguerra, A. Breen, X. Liu, Y. Wu, S. Ringer, Precipitation behaviors of cubic and tetragonal Zr-rich phase in Al-(Si-)Zr alloys, J. Alloys Compd. 674 (2016) $125-130$.

[54] K.E. Knipling, D.C. Dunand, Creep resistance of cast and aged Al-0.1Zr and Al-0.1Zr0.1Ti (at.\%) alloys at 300-400 ${ }^{\circ} \mathrm{C}$, Scr. Mater. 59 (2008) 387-390.

[55] H. Bo, J. Wang, S. Jin, H.Y. Qi, X.L. Yuan, L.B. Liu, Z.P. Jin, Thermodynamic analysis of the Al-Cu-Zr bulk metallic glass system, Intermetallics. 18 (2010) 23222327.

[56] G.E. Dieter, Mechanical metallurgy, Third ed, McGraw-Hill, New York, 1976.

[57] M. Rahimian, N. Parvin, N. Ehsani, Investigation of particle size and amount of alumina on microstructure and mechanical properties of $\mathrm{Al}$ matrix composite made by powder metallurgy, Mater. Sci. Eng. A. 527 (2010) 1031-1038.

[58] M. Rahimian, S. Milenkovic, I. Sabirov, Microstructure and hardness evolution in Mar-M247 Ni-based superalloy processed by controlled cooling and double heat treatment, J. Alloys Compd. 550 (2013) 339-344.

[59] M.A. Otooni, Science and technology of rapid solidification and processing, Springer, 1995.

[60] K.E. Knipling, R.A. Karnesky, C.P. Lee, D.C. Dunand, D.N. Seidman, Precipitation evolution in $\mathrm{Al}-0.1 \mathrm{Sc}, \mathrm{Al}-0.1 \mathrm{Zr}$ and $\mathrm{Al}-0.1 \mathrm{Sc}-0.1 \mathrm{Zr}$ (at.\%) alloys during isochronal aging, Acta Mater. 58 (2010) 5184-5195.

[61] Lijie Zuo, Bing Ye, Jian Feng, Xiangyang Kong, Haiyan Jiang, Wenjiang Ding, Effect of Q-Al5Cu2Mg8Si6 phase on mechanical properties of Al-Si-Cu-Mg alloy at elevated temperature, Mater. Sci. Eng. A. 693 (2017) 26-32. 
[62] C.H. Cáceres, M.B. Djurdjevic, T.J. Stockwell, J.H. Sokolowski, The effect of Cu content on the level of microporosity in Al-Si-Cu-Mg casting alloys, Scr. Mater. 40 (1999) 631-637. 


\section{Figure captions:}

Fig. 1. Optical micrographs showing the microstructure of ( $\mathrm{a}$ and $\mathrm{b}$ ) the Al7Si0.5Cu alloy and (c and d) the Al7Si2Cu0.2Zr alloy under (a and c) as-cast and (b and d) T6 heat-treated conditions.

Fig. 2. Backscatter SEM (BS-SEM) micrographs and related EDS analysis of different phases in Al7Si0.5Cu alloy under (a) as-cast and (b) T6 heat-treated condition.

Fig. 3. (a) BS-SEM micrograph showing the microstructure of the Al7Si2Cu0.2Zr alloy under as-cast condition and (b-e) the corresponding EDS analysis of different phases in the Al7Si2Cu0.2Zr alloy.

Fig. 4. (a and b) BS-SEM micrographs of the Al7Si2Cu0.2Zr alloy under T6 heat-treated condition and (c-g) the related EDS analysis of different phases in the Al7Si2Cu0.2Zr alloy.

Fig. 5. (a) Bright field TEM micrograph of T6 heat-treated Al7Si0.5Cu alloy showing the morphology of $\beta^{\prime \prime}$ and $\theta^{\prime}$ phases, (b) corresponding SADP , (c) high resolution TEM (HRTEM) image showing the morphology of embedded $\beta^{\prime \prime}$ phase, (d) Fast Fourier transformation (FFT) of $\beta$ " phase.

Fig. 6. Bright field TEM images along the [001]Al axis from the T6 heat-treated Al7Si2Cu0.2Zr alloy showing (a) Al-Si-Cu-Zr and Al-Si-Zr precipitates, (b) corresponding SADP, (c) the Al-Si-Cu-Zr precipitate, (d) TEM-EDS analysis of the Al-Si-Cu-Zr precipitate, (e) the Al-Si-Zr precipitate and (f) TEM-EDS analysis of the Al-Si-Zr precipitate.

Fig. 7. (a) Bright field TEM images showing the morphology of $\theta^{\prime}$ and $Q^{\prime}$ phases in the T6 heat-treated Al7Si2Cu0.2Zr alloy, the insert is the corresponding SADP, (b) HRTEM image showing the morphology of $\theta^{\prime}$ phase and the insert showing the FFT of the $\theta^{\prime}$ phase, (c) HRTEM image of Q' lying on the $\{100\}$ plane and insert showing the FFT 
of the $Q^{\prime}$ phase.

Fig. 8. High resolution secondary electron SEM (SE-SEM) micrographs of the Al7Si2Cu0.2Zr alloy under (a) as-cast condition and (b) after heat treatment at $530{ }^{\circ} \mathrm{C}$ for 6h.

Fig. 9. HRTEM micrographs of the T6 heat-treated Al7Si2Cu0.2Zr alloy showing (a) coherent and (b) incoherent interfaces of the $\mathrm{Al}-\mathrm{Si}-\mathrm{Zr}$ precipitate with $\alpha$-Al matrix.

Fig. 10. Yield strength (YS) at ambient temperature and $200{ }^{\circ} \mathrm{C}$ of the experimental alloys under as-cast and T6 heat-treated conditions.

Fig. 11. Ultimate tensile strength (UTS) at ambient temperature and $200{ }^{\circ} \mathrm{C}$ of the experimental alloys under as-cast and T6 heat-treated conditions.

Fig. 12. Elongation at ambient temperature and $200{ }^{\circ} \mathrm{C}$ of the experimental alloys under ascast and T6 heat-treated conditions. 


\section{Table captions:}

Table 1. Chemical composition of the Al7Si0.5Cu and Al7Si2Cu0.2Zr alloys.

Table 2. Diffusion data for selected elements solutes in $\alpha$-Al [1]. 


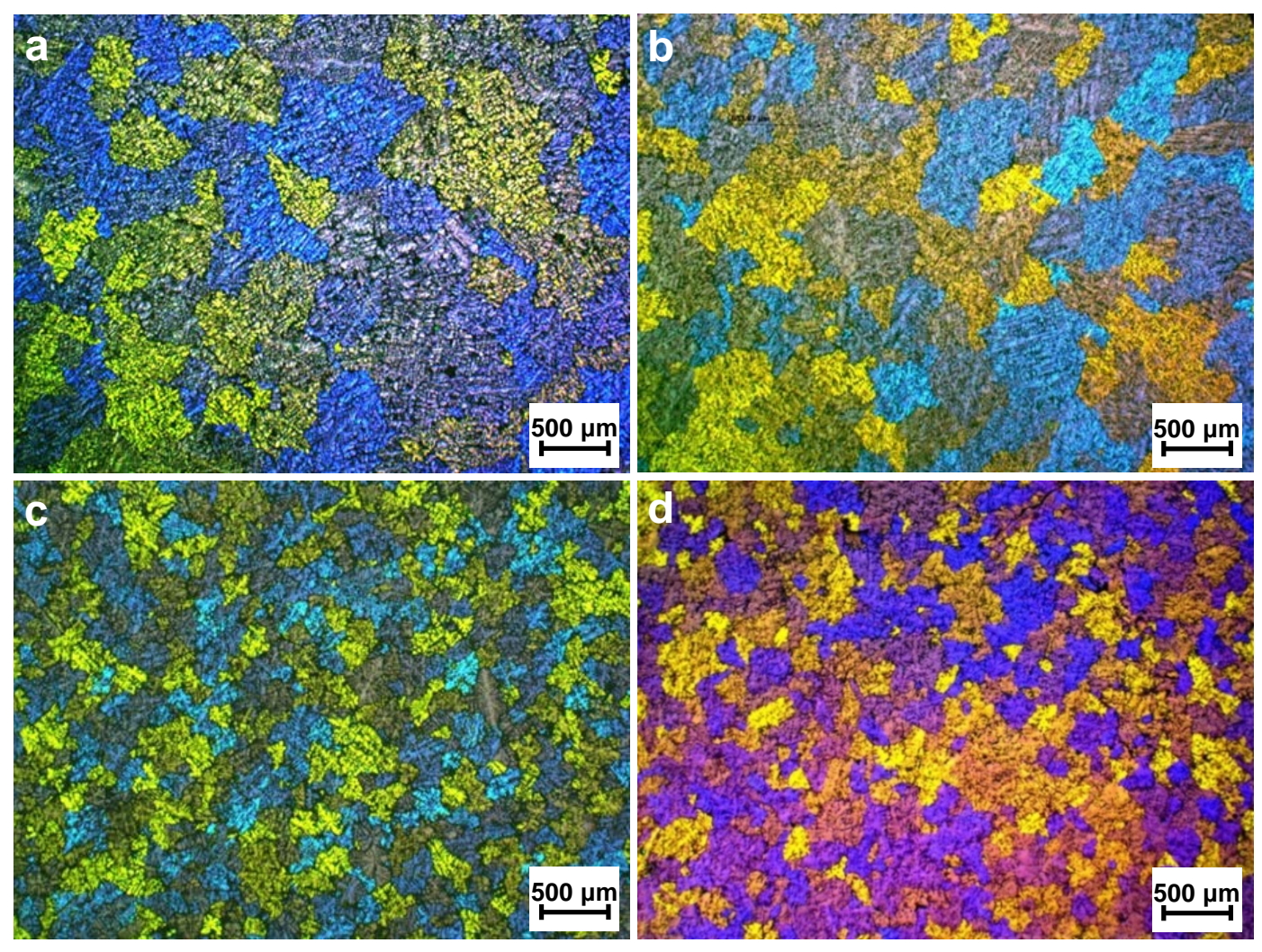

Fig. 1. Optical micrographs showing the microstructure of (a and b) the Al7Si0.5Cu alloy and (c and d) the Al7Si2Cu0.2Zr alloy under (a and c) as-cast and (b and d) T6 heat-treated conditions. 

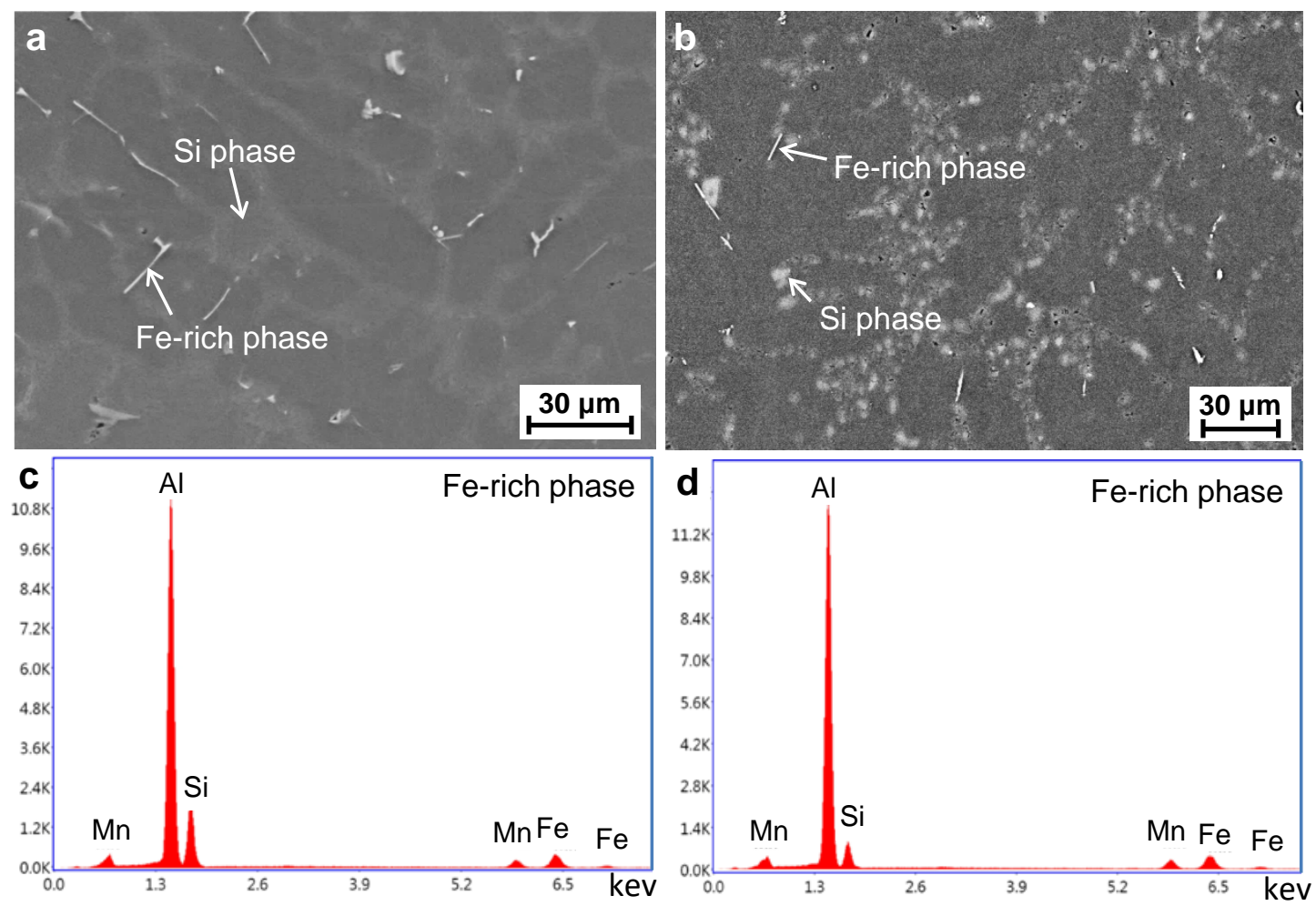

Fig. 2. Backscatter SEM (BS-SEM) micrographs and related EDS analysis of different phases in Al7Si0.5Cu alloy under (a) as-cast and (b) T6 heat-treated condition. 




Fig. 3. (a) BS-SEM micrograph showing the microstructure of the Al7Si2Cu0.2Zr alloy under as-cast condition and (b-e) the corresponding EDS analysis of different phases in the Al7Si2Cu0.2Zr alloy. 

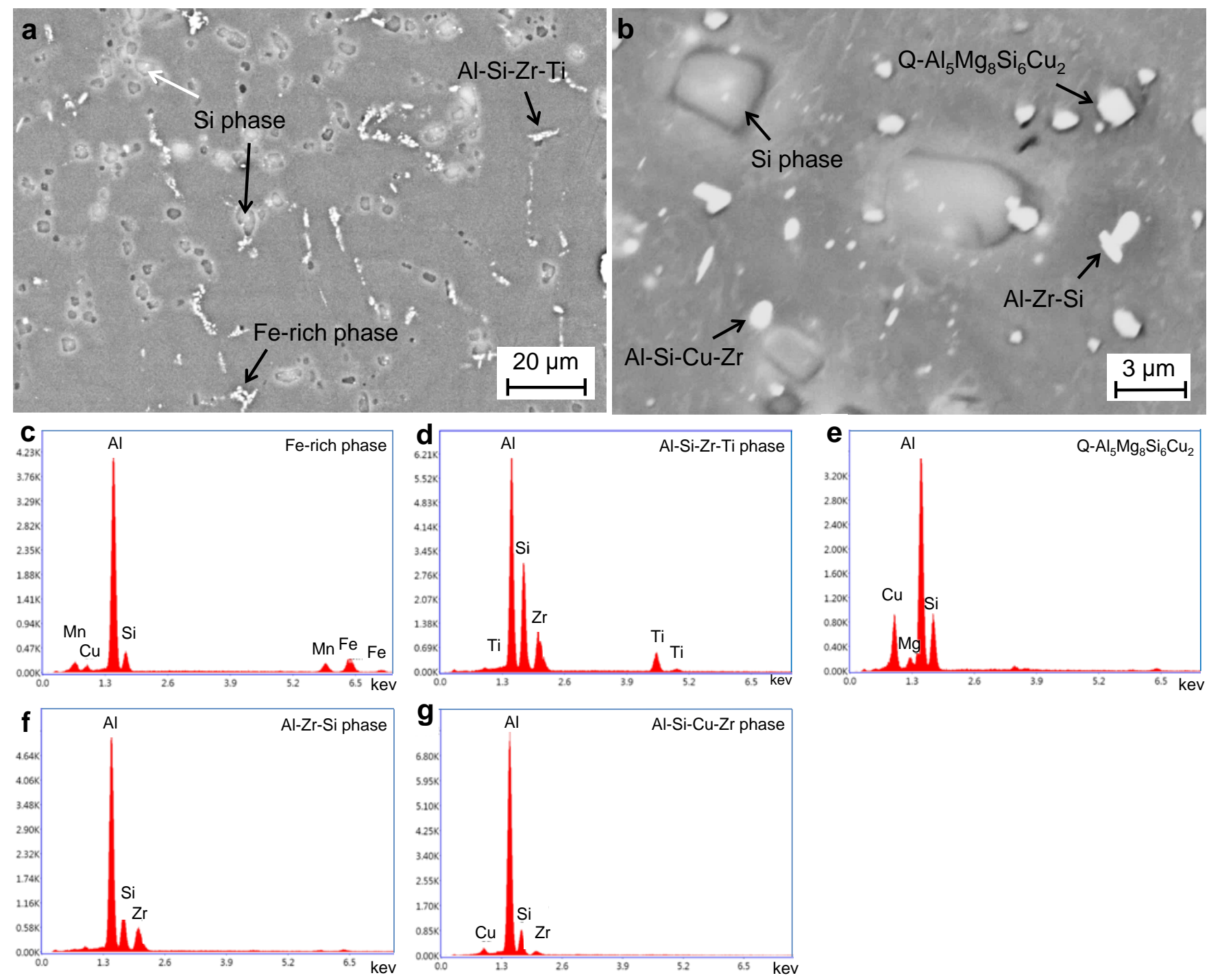

Fig. 4. (a and b) BS-SEM micrographs of the Al7Si2Cu0.2Zr alloy under T6 heat-treated condition and (c-g) the related EDS analysis of different phases in the Al7Si2Cu0.2Zr alloy. 

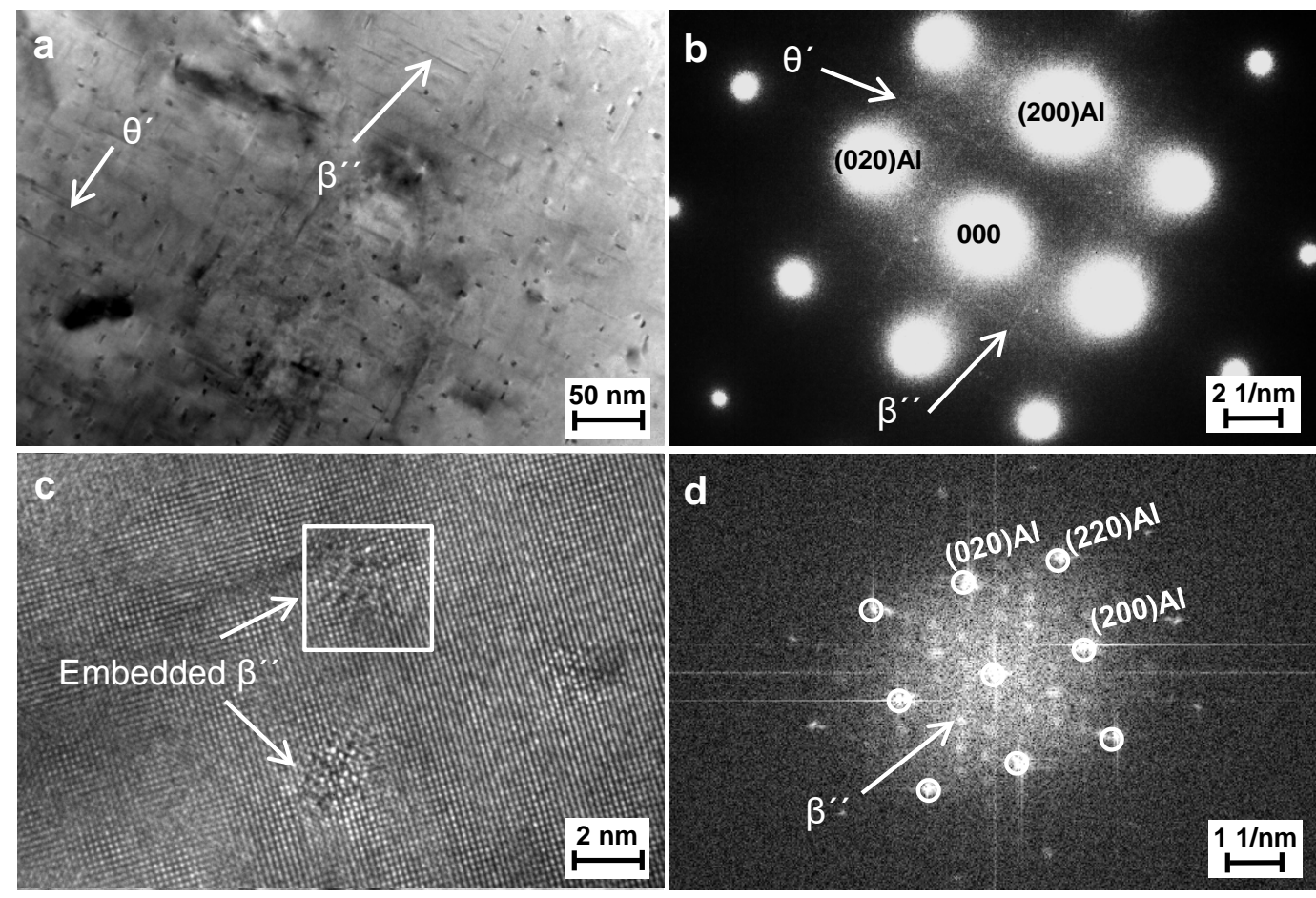

Fig. 5. (a) Bright field TEM micrograph of T6 heat-treated Al7Si0.5Cu alloy showing the morphology of $\beta^{\prime \prime}$ and $\theta^{\prime}$ phases, (b) corresponding SADP , (c) high resolution TEM (HRTEM) image showing the morphology of embedded $\beta^{\prime \prime}$ phase, (d) Fast Fourier transformation (FFT) of $\beta^{\prime \prime}$ phase. 

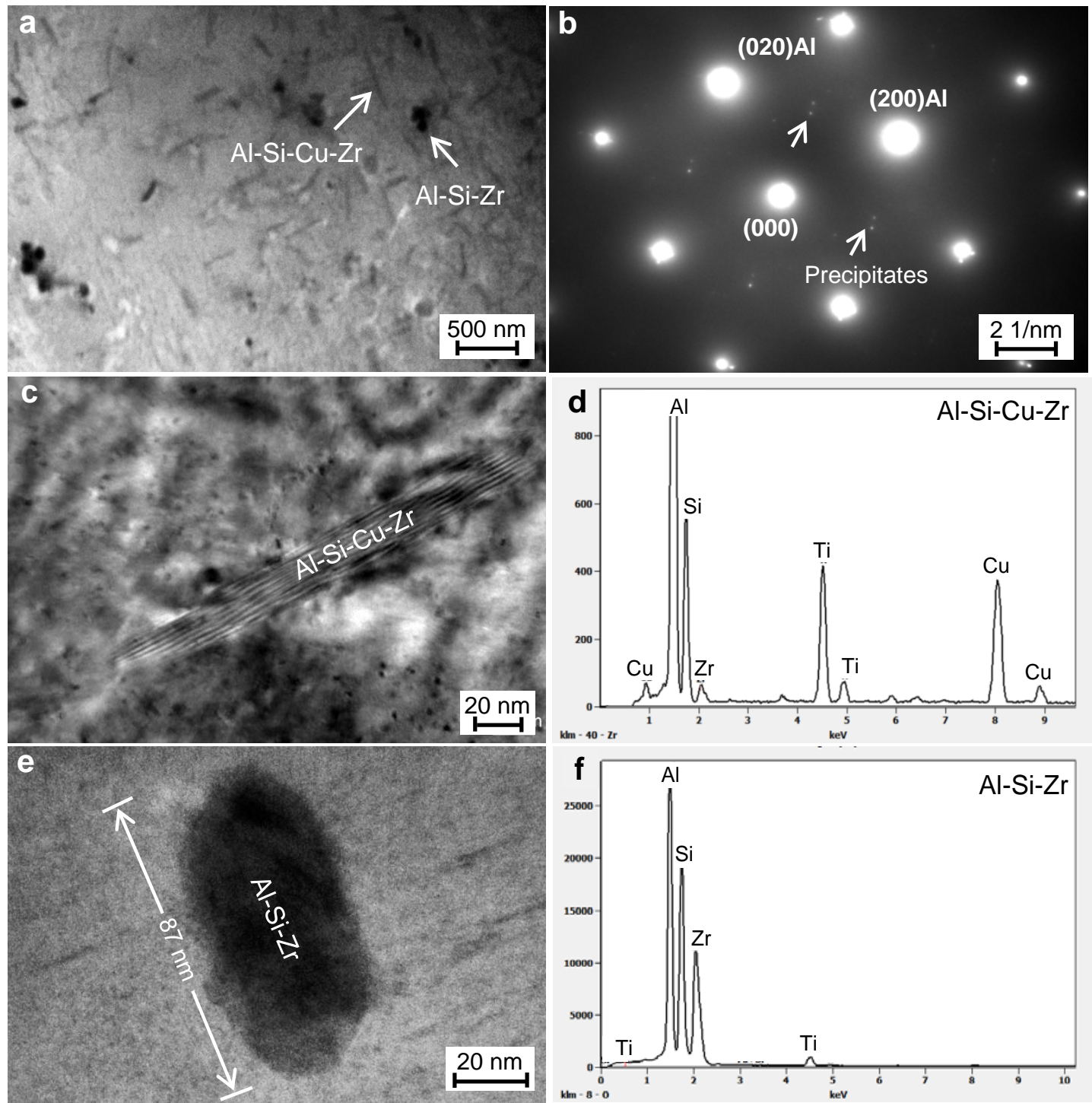

Fig. 6. Bright field TEM images along the $[001]_{\mathrm{Al}}$ axis from the T6 heat-treated Al7Si2Cu0.2Zr alloy showing (a) Al-Si-Cu-Zr and Al-Si-Zr precipitates, (b) corresponding SADP, (c) the Al-Si-Cu-Zr precipitate, (d) TEM-EDS analysis of the Al-Si-Cu-Zr precipitate, (e) the Al-Si-Zr precipitate and (f) TEM-EDS analysis of the Al-Si-Zr precipitate. 


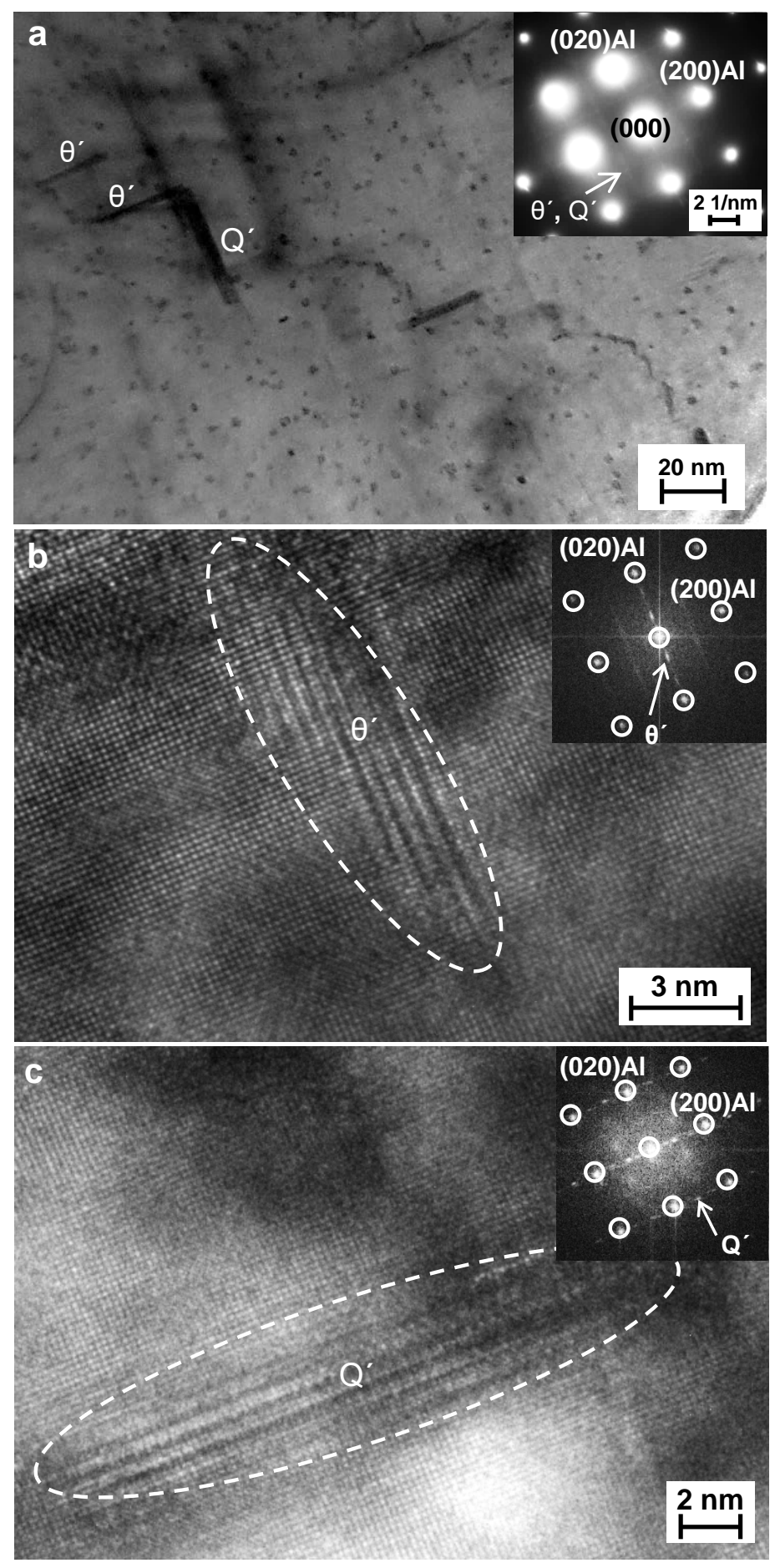

Fig. 7. (a) Bright field TEM images showing the morphology of $\theta^{\prime}$ and $\mathrm{Q}^{\prime}$ phases in the T6 heattreated Al7Si2Cu0.2Zr alloy, the insert is the corresponding SADP, (b) HRTEM image showing the morphology of $\theta^{\prime}$ phase and the insert showing the FFT of the $\theta^{\prime}$ phase, (c) HRTEM image of Q' lying on the $\{100\}$ plane and insert showing the FFT of the Q' phase. 

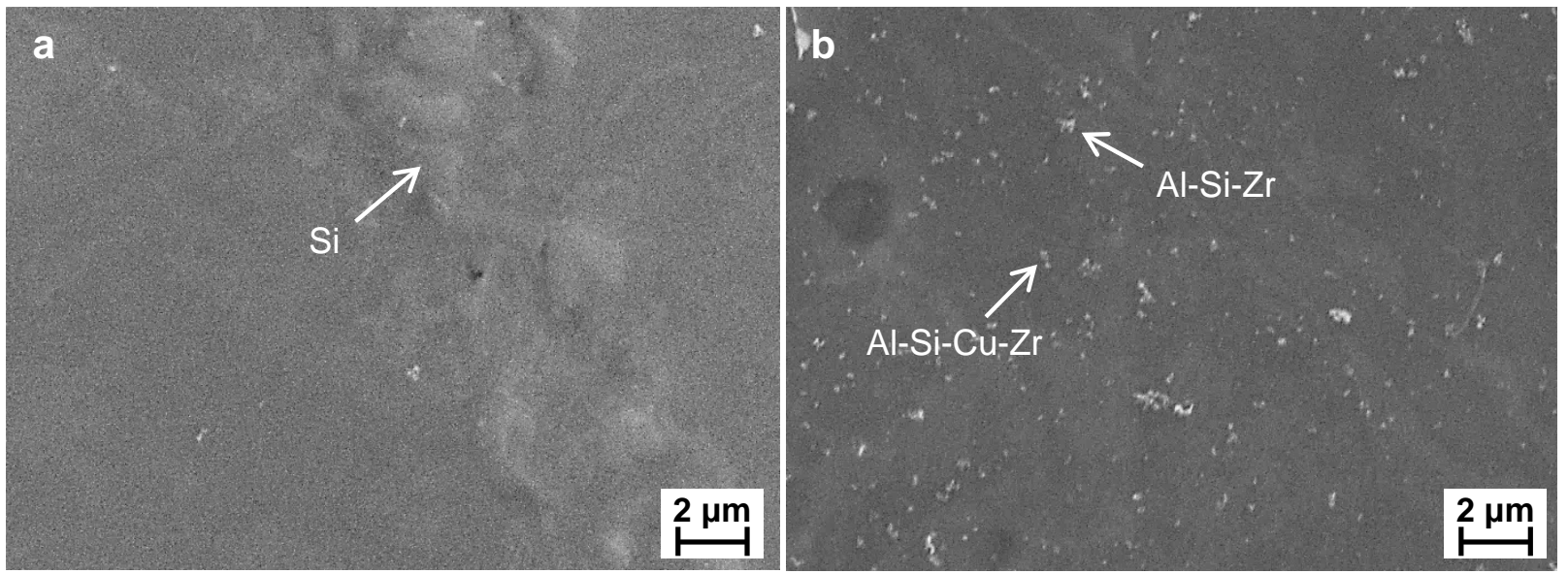

Fig. 8. High resolution secondary electron SEM (SE-SEM) micrographs of the Al7Si2Cu0.2Zr alloy under (a) as-cast condition and (b) after heat treatment at $530^{\circ} \mathrm{C}$ for $6 \mathrm{~h}$. 

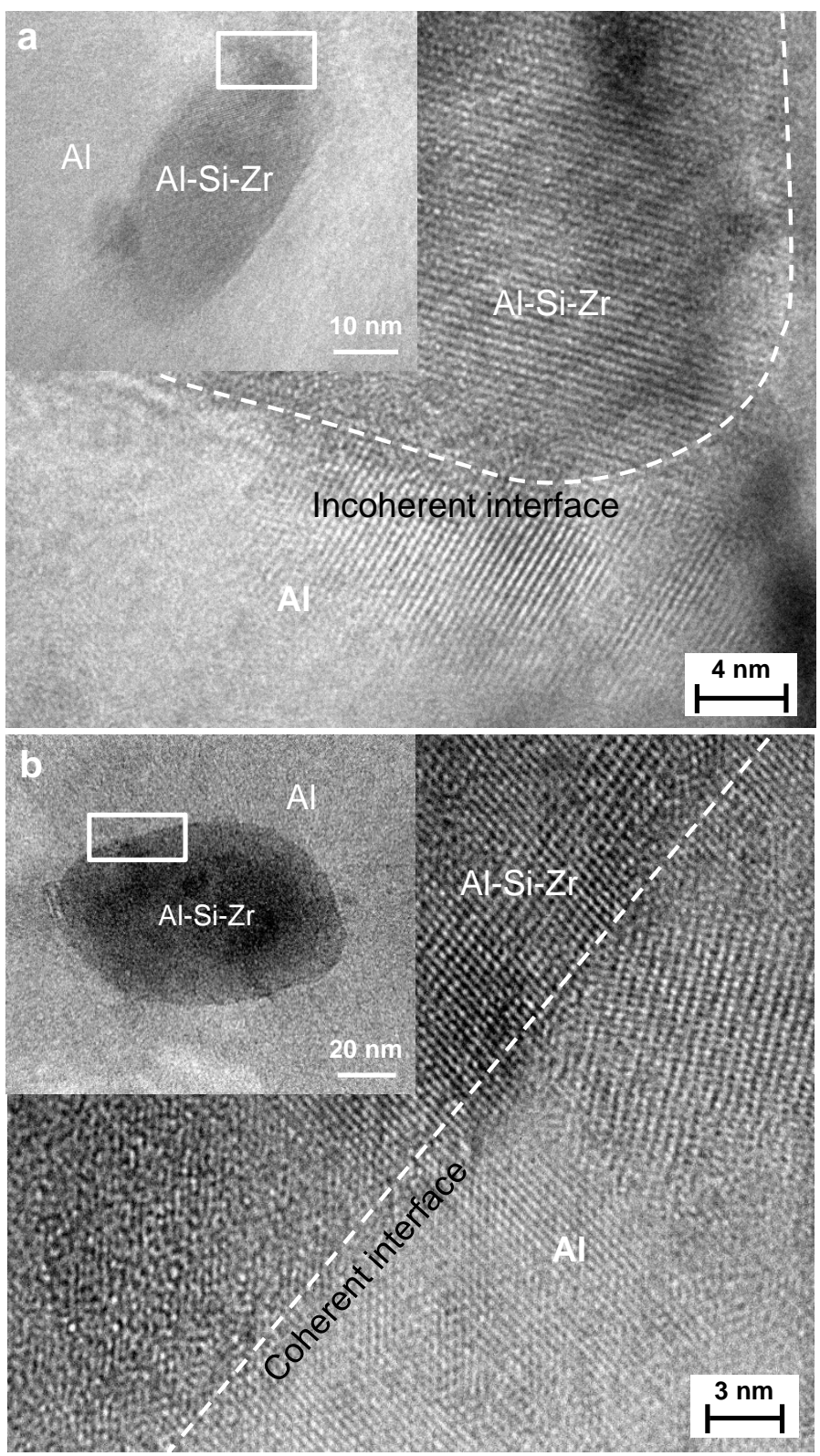

Fig. 9. HRTEM micrographs of the T6 heat-treated Al7Si2Cu0.2Zr alloy showing (a) coherent and (b) incoherent interfaces of the Al-Si-Zr precipitate with $\alpha$-Al matrix. 


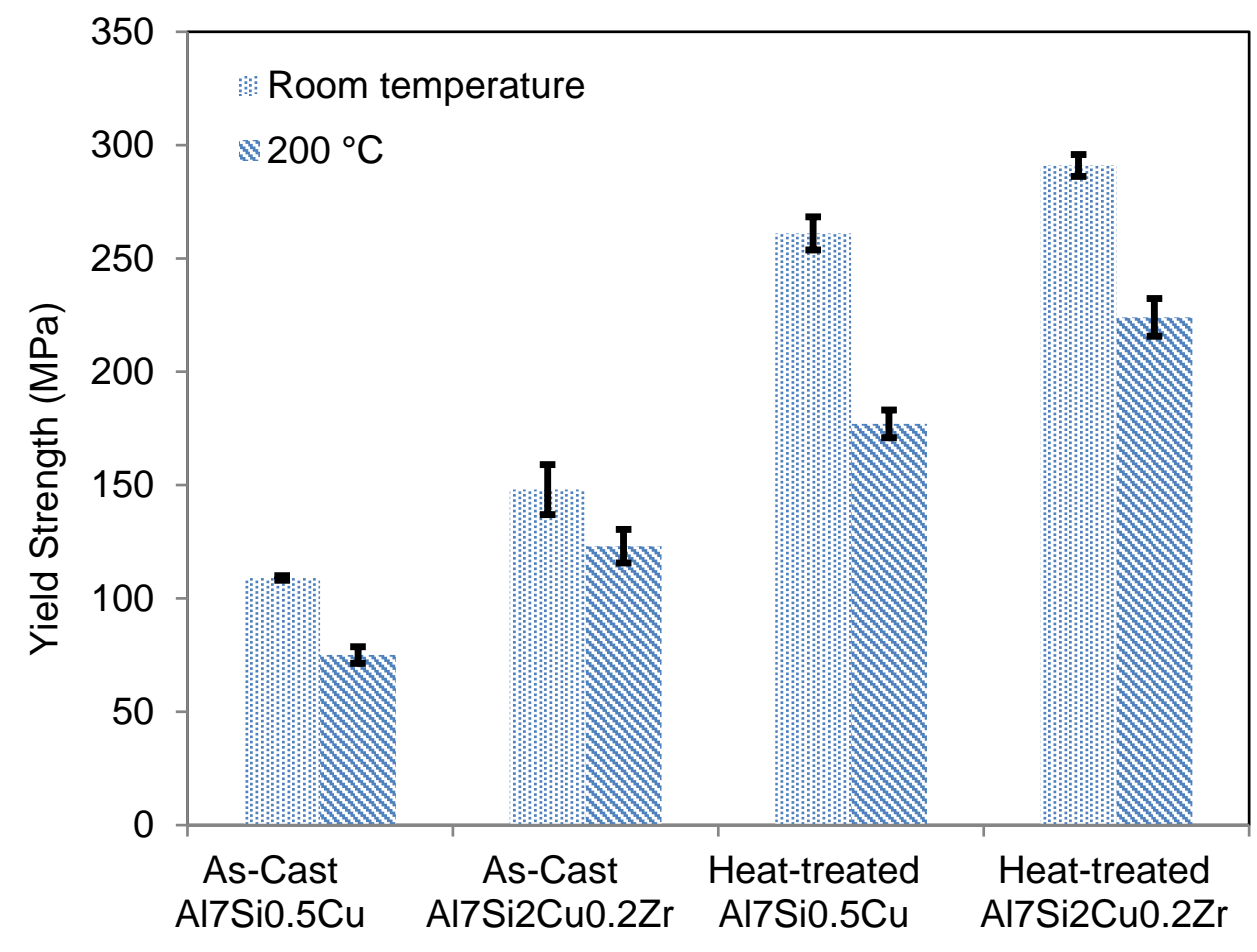

Fig. 10. Yield strength (YS) at ambient temperature and $200{ }^{\circ} \mathrm{C}$ of the experimental alloys under as-cast and T6 heat-treated conditions. 


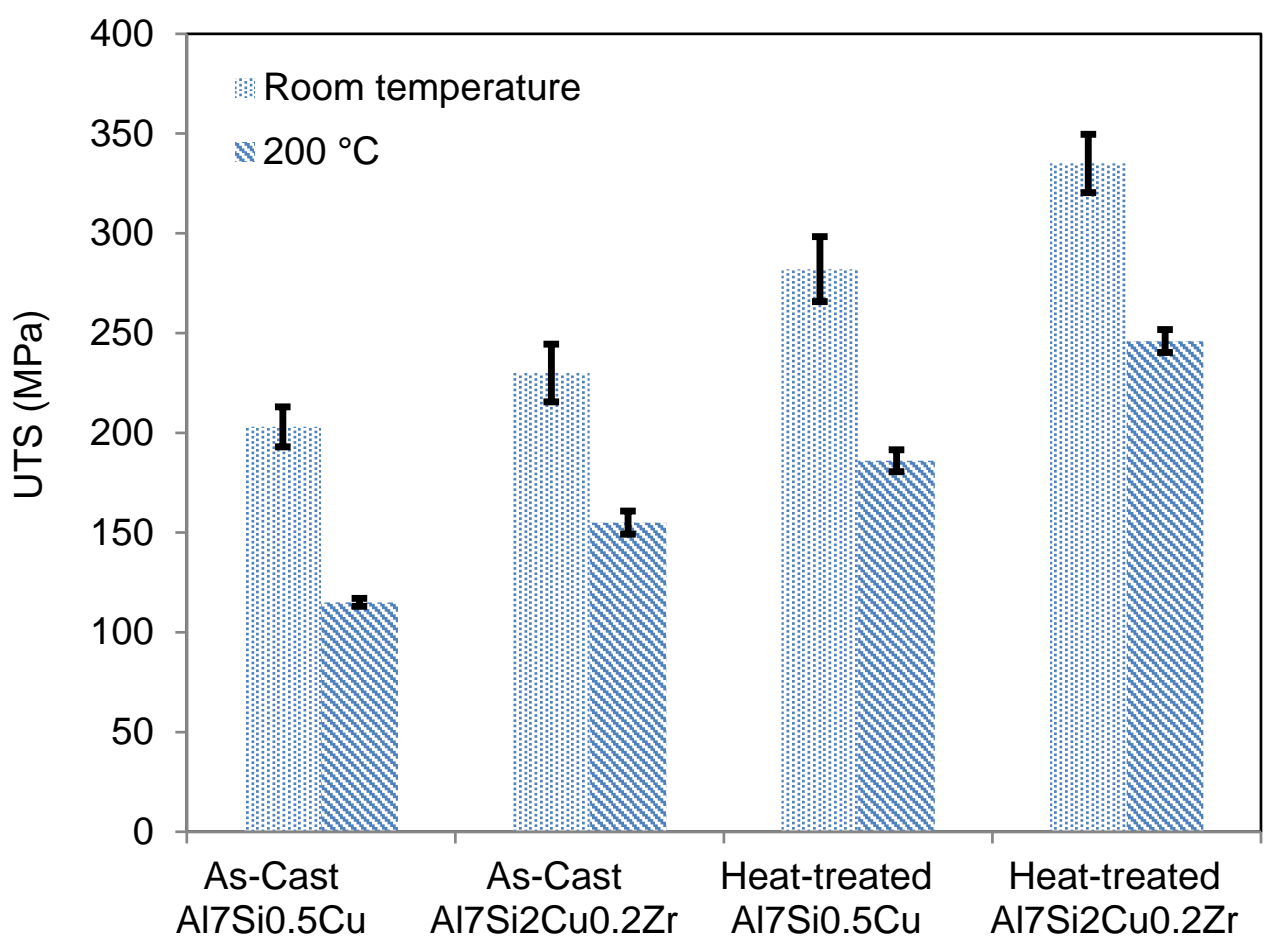

Fig. 11. Ultimate tensile strength (UTS) at ambient temperature and $200{ }^{\circ} \mathrm{C}$ of the experimental alloys under as-cast and T6 heat-treated conditions. 




Fig. 12. Elongation at ambient temperature and $200{ }^{\circ} \mathrm{C}$ of the experimental alloys under as-cast and T6 heat-treated conditions. 
Table 1. Chemical composition of the Al7Si0.5Cu and Al7Si2Cu0.2Zr alloys.

\begin{tabular}{lccccccccc}
\hline Elements (wt. \%) & $\mathrm{Si}$ & $\mathrm{Cu}$ & $\mathrm{Mg}$ & $\mathrm{Fe}$ & $\mathrm{Mn}$ & $\mathrm{Sr}$ & $\mathrm{Ti}$ & $\mathrm{Zr}$ & $\mathrm{Al}$ \\
\hline Al7Si0.5Cu & 6.8 & 0.48 & 0.3 & 0.09 & 0.06 & 0.015 & 0.2 & - & Bal. \\
\hline Al7Si2Cu0.2Zr & 7.1 & 1.99 & 0.29 & 0.1 & 0.07 & 0.012 & 0.2 & 0.2 & Bal. \\
\hline
\end{tabular}


Table 2. Diffusion data for selected elements solutes in $\alpha$-Al [1].

\begin{tabular}{cccc}
\hline Element & $\begin{array}{c}\text { Pre-exponential, Do } \\
\left(\mathrm{m}^{2} \mathrm{~S}^{-1}\right)\end{array}$ & $\begin{array}{c}\text { Activation enthalpy, Q } \\
\left(\mathrm{kJ} \mathrm{mol}^{-1}\right)\end{array}$ & $\begin{array}{c}\mathrm{D} \text { at } 400{ }^{\circ} \mathrm{C} \\
\left(\mathrm{M}^{2} \mathrm{~S}^{-1}\right)\end{array}$ \\
\hline $\mathrm{Al}$ & $1.37 \times 10^{-5}$ & 124 & $3.25 \times 10^{-15}$ \\
\hline $\mathrm{Zr}$ & $7.28 \times 10^{-2}$ & 242 & $1.2 \times 10^{-20}$ \\
\hline $\mathrm{Ti}$ & $1.12 \times 10^{-1}$ & 260 & $7.39 \times 10^{-22}$ \\
\hline $\mathrm{Cu}$ & $6.54 \times 10^{-5}$ & 136 & $1.54 \times 10^{-15}$ \\
\hline
\end{tabular}

